\title{
Utilization of pain and sedation therapy on noninvasive mechanical ventilation in Korean intensive care units: a multi-center prospective observational study
}

\author{
Taehee Kim ${ }^{1}$, Jung Soo Kim ${ }^{2}$, Eun Young Choi ${ }^{3}$, Youjin Chang ${ }^{4}$, Won-Il Choi ${ }^{5}$, Jae-Joon Hwang ${ }^{6}$, \\ Jae Young Moon ${ }^{7}$, Kwangha Lee ${ }^{8}$, Sei Won Kim ${ }^{9}$, Hyung Koo Kang ${ }^{10}$, Yun Su Sim ${ }^{1}$, Tai Sun Park ${ }^{11}$, \\ Seung Yong Park ${ }^{12}$, Sunghoon Park ${ }^{13}$, Jae Hwa Cho ${ }^{14}$, on behalf of the Korean NIV Study Group \\ ${ }^{1}$ Department of Pulmonary, Allergy and Critical Care Medicine, Hallym University Kangnam Sacred Heart Hospital, Seoul; ${ }^{2}$ Department of Pulmonary and \\ Critical Care Medicine, Inha University College of Medicine, Incheon; ${ }^{3}$ Department of Pulmonary and Critical Care Medicine, Yeungnam University Hospital, \\ Daegu: ${ }^{4}$ Department of Pulmonary and Critical Care Medicine, Inje University Sanggye Paik Hospital, Seoul; ${ }^{5}$ Department of Internal Medicine, Myongji \\ Hospital, Goyang; ${ }^{6}$ Department of Pulmonary and Critical Care Medicine, Kyung Hee University Hospital at Gangdong, Seoul,; Department of Pulmonary \\ and Critical Care Medicine, Chungnam National University Hospital, Daejeon; ${ }^{8}$ Department of Internal Medicine, Pusan National University Hospital, Busan; \\ ${ }^{9}$ Department of Pulmonary, Critical Care and Sleep Medicine, St. Paul's Hospital, College of Medicine, The Catholic University of Korea, Seoul, ${ }^{10}$ Division of \\ Pulmonary and Critical Care Medicine, Department of Internal Medicine, Inje University Ilsan Paik Hospital, Goyang; ${ }^{11}$ Department of Internal Medicine, \\ Hanyang University Guri Hospital, Guri, ${ }^{12}$ Department of Pulmonary, Allergy and Critical Care Medicine, Jeonbuk National University Hospital, Jeonju; \\ ${ }^{13}$ Department of Pulmonary, Allergy and Critical Care Medicine, Hallym University Sacred Heart Hospital, Anyang: ${ }^{14}$ Department of Internal Medicine, \\ Gangnam Severance Hospital, Yonsei University College of Medicine, Seoul, Korea
}

Background: The use of sedative drugs may be an important therapeutic intervention during noninvasive ventilation (NIV) in intensive care units (ICUs). The purpose of this study was to assess the current application of analgosedation in NIV and its impact on clinical outcomes in Korean ICUs.

Methods: Twenty Korean ICUs participated in the study, and data was collected on NIV use during the period between June 2017 and February 2018. Demographic data from all adult patients, NIV clinical parameters, and hospital mortality were included.

Results: A total of 155 patients treated with NIV in the ICUs were included, of whom 26 received pain and sedation therapy (sedation group) and 129 did not (control group). The primary cause of ICU admission was due to acute exacerbation of obstructed lung disease (45.7\%) in the control group and pneumonia treatment (53.8\%) in the sedation group. In addition, causes of NIV application included acute hypercapnic respiratory failure in the control group (62.8\%) and post-extubation respiratory failure in the sedation group (57.7\%). Arterial partial pressure of carbon dioxide $\left(\mathrm{PaCO}_{2}\right)$ levels before and after 2 hours of NIV treatment were significantly decreased in both groups: from $61.9 \pm 23.8 \mathrm{~mm} \mathrm{Hg}$ to $54.9 \pm 17.6 \mathrm{~mm} \mathrm{Hg}$ in the control group $(P<0.001)$ and from $54.9 \pm 15.1 \mathrm{~mm} \mathrm{Hg}$ to $51.1 \pm 15.1 \mathrm{~mm} \mathrm{Hg}$ in the sedation group $(P=0.048)$. No significant differences were observed in the success rate of NIV weaning, complications, length of ICU stay, ICU survival rate, or hospital survival rate between the groups.

Conclusions: In NIV patients, analgosedation therapy may have no harmful effects on complications, NIV weaning success, and mortality compared to the control group. Therefore, sedation during NIV may not be unsafe and can be used in patients for pain control when indicated.

Key Words: intensive care units; noninvasive ventilation; safety; sedatives

\section{Original Article}

Received: March 15, 2020

Revised: May 22, 2020

Accepted: September 10, 2020

\section{Corresponding author}

Jae Hwa Cho

Division of Pulmonary and Critical Care Medicine, Department of Internal Medicine, Gangnam Severance Hospital, Yonsei University College of Medicine, 211 Eonju-ro, Gangnam-gu, Seoul 06273, Korea Tel: +82-2-2019-3345

Fax: +82-2-3463-3882

E-mail: jhcho66@yuhs.ac

Copyright $(\odot 2020$ The Korean Society of Critical Care Medicine

This is an Open Access article distributed under the terms of Creative Attributions Non-Commercial License (https:// creativecommons.org/li-censes/by-nc/4.0/ which permits unrestricted noncommercial use, distribution, and reproduction in any medium, provided the original work is properly cited. 


\section{INTRODUCTION}

Noninvasive positive pressure ventilation is increasingly being used for the treatment of patients with acute respiratory failure [1]. The clinical benefits of this therapeutic technique have proven efficacious in various respiratory failure conditions: the acute respiratory acidosis in exacerbations of chronic obstructive lung disease (COPD); the hypoxemia derived from cardiogenic pulmonary edema [2]; the hypoxic respiratory failure observed in immunocompromised patients [3]; and in patients with advanced neuromuscular disorders such as amyotrophic lateral sclerosis. Despite the clear advantages of noninvasive ventilation (NIV) when used in critically ill patients, it remains associated with large failure rates due to patient discomfort or refusal. Recent studies have shown that NIV failure rates are approximately $40 \%$, which remains a challenging barrier for the implementation of this effective technique [4].

Analgesia-based sedation is a common intervention used to increase the tolerance of patients who have to be supported using invasive ventilation. Similarly, there has been an effort to reduce the discomfort and refusal of patients utilizing NIV. Conti et al. [5] showed that the continuous infusion of sufentanil in patients undergoing NIV had no significant effects on respiratory variables or hemodynamic changes. However, sufentanil is a long-acting opioid, and the long-term infusion may induce the accumulation phenomena, which can delay patient recovery and augment the risk of respiratory depression [6]. Recent studies have demonstrated the safety and efficacy of analgosedation in patients with NIV failure, using drugs such as remifentail, dexmedetomidine, and propofol [7-11]. Nonetheless, clinicians hesitate to use these analgosedative pharmacologics as they may also cause respiratory depression in NIV patients.

The aim of this study was to assess the current application of analgosedation in NIV and its impact on clinical outcomes. As such, we conducted a multicenter prospective observational study in Korean intensive care units (ICUs) which employ the NIV technique.

\section{MATERIALS AND METHODS}

\section{Study Population}

Twenty ICU intensivists belonging to Korean national hospitals participated in the study and collected data on NIV use during the period between June 2017 and February 2018. Adult patients (aged $>18$ years) who were admitted to these

\section{KEY MESSAGES}

- Analgosedation therapy rate of use during noninvasive ventilation (NIV) in Korean intensive care units (ICUs) was $16.8 \%$ (26/155 patients).

- There were no significant differences in the success rate of NIV weaning, complications, length of ICU stay, ICU survival rate, or hospital survival rate between the control and sedation groups.

- The application of analgosedation may not be harmful for patients with NIV if necessary to control pain and provide sedation.

ICUs and received NIV treatment for acute respiratory failure were prospectively included. This data was one part of a nationwide data collection study on NIV in Korean ICUs [12]. The indications for NIV included the following: (1) acute hypercapnic respiratory failure, which was designated as respiratory failure occurring in a patient with chronic lung disease (obstructive or restrictive) and, (2) de novo respiratory failure, typically indicating respiratory failure in patients without chronic respiratory disease, primarily found in those with hypoxemic respiratory failure (e.g., pneumonia, postoperative respiratory failure, sepsis, or acute respiratory distress syndrome) $[13,14]$. We included do-not-resuscitate patients who received NIV in this study. We excluded the clinical data of those who refused informed consent.

Each Ethical Committee from all participating hospitals approved this study, and the Institutional Review Board of Hallym University also approved this study (IRB No. 2017-I049). Informed consent was obtained from all enrolled patients or their legal surrogates. We also performed a secondary analysis of NIV data in Korean ICUs. We compared the baseline characteristics and clinical data of patients receiving NIV with or without the use of pain and sedative drugs.

\section{Data Collection and Outcomes}

We collected demographic characteristics and the following data: comorbidities, presence and type of any underlying lung diseases, the primary causes of ICU admission and NIV treatment, mental status (the Richmond Agitation Sedation Score [RASS]), and the severity of the illness (the Sequential Organ Failure Assessment [SOFA]) immediately prior to the implementation of NIV. We also included the following in our analysis: arterial blood gas analysis (ABGA), vital signs, lactate level before and 2 hours after NIV, and the location where NIV was first implemented. While we collected the name of the 
pain control and sedation drugs during NIV, we did not obtain information on the dose or duration. We also collected the specific type of NIV machine used, the NIV settings (i.e., main NIV modes, fractional inspired oxygen $\left[\mathrm{FiO}_{2}\right]$, inspiratory positive airway pressure [IPAP], expiratory positive airway pressure [EPAP], and tidal volume), and the mean duration of use (hr/day).

The following patient outcomes were examined: treatment success, treatment failure, complications from NIV treatment, length of NIV use, length of ICU stay, and ICU and hospital mortality rates. Treatment success was defined as: (1) successful weaning from NIV or (2) transfer from the ICU to a general ward in a stable state with the NIV device in place [15]. Treatment failure was defined as: (1) intubation and mechanical ventilation (MV), (2) tracheostomy, (3) hopeless discharge with a NIV device, (4) death during NIV treatment, or (5) change to the high-flow nasal cannula with no clinical improvement [16]. Patients who died within 24 hours of NIV weaning were also classified as a NIV failure [17]. A large leak was defined as a leak flow rate $>60 \mathrm{~L} / \mathrm{min}$, or when the attending doctor considered the leak too large to continue treatment.

\section{Statistical Analysis}

In this observational study, most statistical analyses were descriptive as the authors aimed to observe the current status of NIV use. All categorical variables are presented as numbers with percentages and were compared using the chi-square or Fisher's exact test as indicated. All continuous variables are summarized and reported as means with standard deviations or medians with interquartile ranges. The normality test was conducted using the Shapiro-wilk test. The Student t-test was used if the variables had a normal distribution and the MannWhitney U-test was used if the variables had a skewed distribution. A paired t-test and the Wilcoxon signed-rank test were also used to compare the values before and after NIV use. Statistical analysis was performed using IBM SPSS ver. 22.0 (IBM Corp., Armonk, NY, USA) and the R statistical package version 4.0.0 (R Foundation, Vienna, Austria).

\section{RESULTS}

\section{Baseline Characteristics}

The baseline demographics of each group are summarized in Table 1. During the study period, a total of 155 patients treated with NIV were enrolled from 20 ICUs. This included 129 patients $(83.2 \%)$ who did not undergo pain or sedation treat-
Table 1. Baseline demographics and characteristics of the study population

\begin{tabular}{|c|c|c|c|}
\hline Variable & $\begin{array}{c}\text { Control } \\
(n=129)\end{array}$ & $\begin{array}{l}\text { Sedation } \\
(n=26)\end{array}$ & P-value \\
\hline Age (yr) & $71.7 \pm 11.5$ & $71.7 \pm 11.4$ & $>0.05$ \\
\hline Male sex & $78(60.5)$ & $17(65.4)$ & $>0.05$ \\
\hline SOFA score at NIV start & $4.16 \pm 0.24$ & $4.27 \pm 0.46$ & $>0.05$ \\
\hline RASS at NIV start & $-0.53 \pm 1.06$ & $-0.11 \pm 1.11$ & 0.17 \\
\hline Comorbidity & & & $>0.05$ \\
\hline DM & $37(28.7)$ & $2(7.7)$ & 0.02 \\
\hline HTN & $51(39.5)$ & $11(42.3)$ & \\
\hline Prior lung resection & $6(4.7)$ & $2(7.7)$ & \\
\hline Coronary artery disease & $16(12.4)$ & $4(15.4)$ & \\
\hline Hear failure & $29(22.5)$ & $5(19.2)$ & \\
\hline CKD & $17(13.2)$ & $3(11.5)$ & \\
\hline LC & $6(4.7)$ & $1(3.8)$ & \\
\hline CVA & $15(11.6)$ & $5(19.2)$ & \\
\hline Cancer & $10(7.8)$ & $3(11.5)$ & \\
\hline Immunocompromised state & $8(6.2)$ & $1(3.8)$ & \\
\hline Underlying lung disease & & & $>0.05$ \\
\hline Normal & $35(27.1)$ & $6(23.1)$ & \\
\hline COPD & $44(34.1)$ & $10(38.5)$ & \\
\hline Bronchial asthma & $3(2.3)$ & 0 & \\
\hline ILD & $4(3.1)$ & $2(7.7)$ & \\
\hline Bilateral bronchiectasis & $7(5.4)$ & $3(11.5)$ & \\
\hline TB-destroyed lung & $15(11.6)$ & $3(11.5)$ & \\
\hline Neuromuscular & $6(4.7)$ & 0 & \\
\hline Obesity disorder & $4(3.1)$ & $1(3.8)$ & \\
\hline Kyphoscoliosis & $4(3.1)$ & 0 & \\
\hline Other chest wall disease & $2(1.6)$ & 0 & \\
\hline Obstructive sleep apnea & $3(2.3)$ & 0 & \\
\hline Others & $2(1.6)$ & $1(3.8)$ & \\
\hline
\end{tabular}

Values are presented as mean \pm standard deviation or number (\%). SOFA: sequential organ failure assessment; NIV: noninvasive ventilation; RASS: Richmond Agitation-Sedation Scale; DM: diabetes mellitus; HTN: hypertension; CKD: chronic kidney disease; LC: liver cirrhosis; CVA: cerebrovascular accident; COPD: chronic obstructive pulmonary disease; ILD: interstitial lung disease; TB: tuberculosis.

ment (control group) and 26 patients (16.8\%) who underwent analgosedation during NIV (sedation group) (Figure 1). The mean age of all the enrolled patients was $71.7 \pm 11$.6 years, of whom 95 patients $(61.3 \%)$ were male. At the start of NIV, the mean SOFA score was $4.16 \pm 0.24$ in the control group and $4.27 \pm 0.46$ in the sedation group $(\mathrm{P}>0.05)$. The RASS was $-0.53 \pm 1.06$ in the control group and $-0.11 \pm 1.11$ in the sedation group for mentality evaluation before NIV was applied. 
Hypertension was the most common comorbidity in both groups: $39.5 \%$ (51/129) in the control group and $42.3 \%$ (11/26) in the sedation group $(\mathrm{P}=0.02)$. $\mathrm{COPD}$ as an underlying lung disease was reported $34.1 \%(44 / 129)$ in the control group and $38.5 \%(10 / 26)$ in the sedation group.

The primary cause of ICU admission in the control group was due to the acute exacerbation of obstructed lung disease (45.7\% [59/129]: exacerbation of COPD, 35.7\% [46/129]; exacerbation of bronchial asthma, 3.1\% [4/129]; other obstructive lung diseases, $7.0 \%$ [9/129]). However, the most common cause of ICU admission in the sedation group was pneumonia treatment (14/26, 53.8\%) (Table 2). In addition, the most common causes of NIV application were acute hypercapnic respiratory failure in the control group (62.8\% [81/129]) and post-extubation respiratory failure in the sedation group $(57.7 \%$ [15/26]). NIV was initiated in the ICU in 116 patients (89.9\%) in the control group and $26(100 \%)$ in the sedation group.

\section{Changes in Vital Signs and ABGA}

We compared alterations in vital signs and ABGA results between baseline values before NIV treatment and 2 hours after-

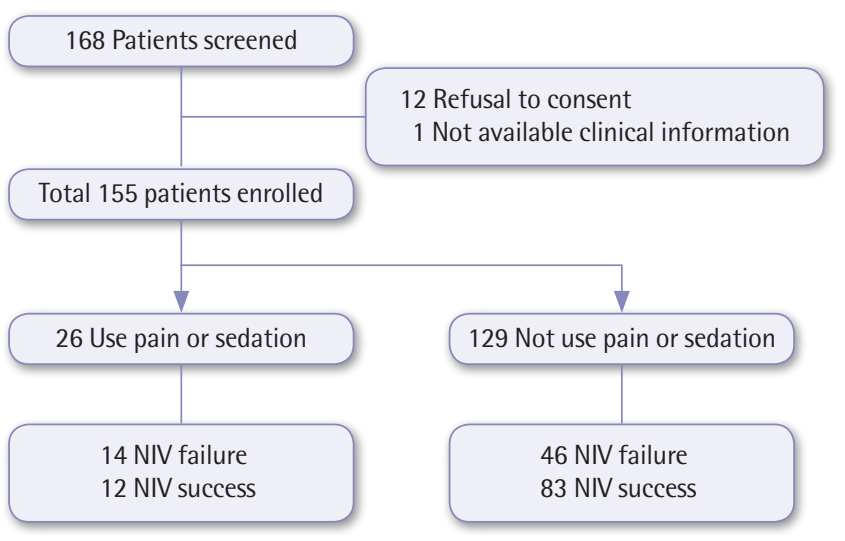

Figure 1. Flowchart of the enrolled patients.
NIV treatment in both groups (Table 3). In the control group, arterial partial pressure of carbon dioxide $\left(\mathrm{PaCO}_{2}\right)$ was significantly reduced from $61.9 \pm 23.8 \mathrm{~mm} \mathrm{Hg}$ before NIV treatment to $54.9 \pm 17.6 \mathrm{~mm} \mathrm{Hg}$ after 2 hours of NIV treatment $(\mathrm{P}<0.001)$. Heart rate (HR) was $95.5 \pm 19.7$ before NIV and $90.7 \pm 16.1$ after 2 hours of NIV treatment $(\mathrm{P}<0.001)$. The respiratory rate $(\mathrm{RR})$

Table 2. Primary causes of ICU admission and NIV application

\begin{tabular}{|c|c|c|c|}
\hline Variable & $\begin{array}{c}\text { Control } \\
(n=129)\end{array}$ & $\begin{array}{c}\text { Sedation } \\
(n=26)\end{array}$ & P-value \\
\hline Primary cause of ICU admission & & & 0.008 \\
\hline Exacerbation of COPD & $46(35.7)$ & $6(23.1)$ & \\
\hline Exacerbation of bronchial asthma & $4(3.1)$ & 0 & \\
\hline Other obstructive lung diseases & $9(7.0)$ & 0 & \\
\hline Pneumonia & $34(26.4)$ & 14 (53.8) & \\
\hline Neuromuscular disease & $3(2.3)$ & 0 & \\
\hline Postoperation & $4(3.1)$ & 0 & \\
\hline Sepsis & $4(3.1)$ & 0 & \\
\hline ARDS & 0 & $4(15.4)$ & \\
\hline Heart failure & $8(6.2)$ & 0 & \\
\hline Myocardial infarct & $1(0.8)$ & 0 & \\
\hline Cardiac arrest & $6(4.7)$ & $1(3.8)$ & \\
\hline Cerebral infarct & $1(0.8)$ & 0 & \\
\hline Others & $8(6.2)$ & $1(3.8)$ & \\
\hline Primary cause of NIV application & & & 0.003 \\
\hline Acute hypercapnic respiratory failure & $81(62.8)$ & $7(26.9)$ & \\
\hline De novo hypoxic respiratory failure & $13(10.1)$ & $4(15.4)$ & \\
\hline Cardiogenic pulmonary edema & $3(2.3)$ & 0 & \\
\hline Post-extubation (for weaning) & $29(22.5)$ & $15(57)$ & \\
\hline Palliation & $2(1.6)$ & 0 & \\
\hline
\end{tabular}

Values are presented as number (\%).

ICU: intensive care unit; NIV: noninvasive ventilation; COPD: chronic obstructive pulmonary disease; ARDS: acute respiratory distress syndrome.

Table 3. Changes in arterial blood gas values, respiratory rate, and hemodynamics

\begin{tabular}{|c|c|c|c|c|c|c|}
\hline \multirow{2}{*}{ Variable } & \multicolumn{3}{|c|}{ Control } & \multicolumn{3}{|c|}{ Sedation } \\
\hline & Pre-NIV & Post-2 hr NIV & P-value & Pre-NIV & Post-2 hr NIV & P-value \\
\hline $\mathrm{pH}$ & $7.35 \pm 0.10$ & $7.39 \pm 0.09$ & 1.000 & $7.40 \pm 0.08$ & $7.41 \pm 0.09$ & 0.777 \\
\hline $\mathrm{PaCO}_{2}(\mathrm{~mm} \mathrm{Hg})$ & $61.9 \pm 23.8$ & $54.9 \pm 17.6$ & $<0.001$ & $54.9 \pm 15.1$ & $51.1 \pm 15.1$ & 0.048 \\
\hline $\mathrm{PaO}_{2} / \mathrm{FiO}_{2}$ & $221 \pm 99.7$ & $237 \pm 93.3$ & 0.992 & $139 \pm 25.1$ & $127 \pm 19.6$ & 0.348 \\
\hline Systolic blood pressure (mm Hg) & $128 \pm 25.8$ & $125 \pm 22.6$ & 0.229 & $139 \pm 25.1$ & $127 \pm 19.6$ & 0.021 \\
\hline Heart rate (/min) & $95.5 \pm 19.7$ & $90.7 \pm 16.1$ & $<0.001$ & $98.2 \pm 23.1$ & $97.5 \pm 22.4$ & 0.554 \\
\hline Respiratory rate (/min) & $24.5 \pm 6.72$ & $23.4 \pm 5.87$ & 0.018 & $26.6 \pm 6.91$ & $26.4 \pm 6.47$ & 0.473 \\
\hline
\end{tabular}

Values are presented as mean \pm standard deviation.

$\mathrm{NIV}$ : noninvasive ventilation; $\mathrm{PaCO}_{2}$ : arterial partial pressure of carbon dioxide; $\mathrm{PaO}_{2}$ : arterial oxygen partial pressure; $\mathrm{FiO}_{2}$ : fractional inspired oxygen. 
was $24.5 \pm 6.72$ before NIV and $23.4 \pm 5.87$ after 2 hours of NIV $(\mathrm{P}=0.018)$. However, $\mathrm{pH}$, ratio of arterial oxygen partial pressure $\left(\mathrm{PaO}_{2}\right)$ to $\mathrm{FiO}_{2}$ (PF ratio), and systolic blood pressure (SBP) did not exhibit interval changes before and after NIV treatment in the control group. In the sedation group, $\mathrm{PaCO}_{2}$ was significantly reduced from $54.9 \pm 15.1 \mathrm{~mm} \mathrm{Hg}$ before NIV treatment to $51.1 \pm 15.1 \mathrm{~mm} \mathrm{Hg}$ after 2 hours of NIV treatment $(\mathrm{P}=0.048)$. SBP was reduced from $139 \pm 25.1 \mathrm{~mm} \mathrm{Hg}$ before NIV to $127 \pm 19.6 \mathrm{~mm} \mathrm{Hg}$ after 2 hours of NIV treatment $(\mathrm{P}=$ 0.021 ). There were no significant differences in $\mathrm{pH}, \mathrm{PF}$ ratio, $\mathrm{HR}$, and RR in the sedation group.

\section{NIV Treatments (Devices, Modes, and Settings)}

The differences in the type of NIV machine and the applied NIV mode were analyzed in both the control and sedation groups. In the control group without sedation, an ICU ventilator with an NIV mode was used for 73 cases (56.6\%), a dedicated NIV was used for 29 cases (22.5\%), and a home care NIV unit was used for 25 cases (19.4\%). In the sedation group, an ICU ventilator with an NIV mode was used for 23 cases (88.5\%), and a dedicated NIV was used for three cases $(11.5 \%$,

Table 4. Clinical outcomes after NIV between the two groups

\begin{tabular}{lccc}
\hline Outcome & $\begin{array}{c}\text { Control } \\
(n=129)\end{array}$ & $\begin{array}{c}\text { Sedation } \\
(n=26)\end{array}$ & P-value \\
\hline NIV failure & $46(35.7)$ & $14(53.8)$ & 0.086 \\
Intubation and MV & $22(17.1)$ & $8(30.8)$ & \\
Tracheostomy & $4(3.1)$ & $3(11.5)$ & \\
Hopeless discharge with NIV & $3(2.3)$ & 0 & \\
Died during NIV & $13(10.1)$ & $2(7.7)$ & \\
Change to HFNC & $11(3.1)$ & $3(11.5)$ & \\
Cause of NIV failure & & & 0.021 \\
Inadequate efficacy & $36(80.0)$ & $8(57.1)$ & \\
No clinical improvement & $22(47.8)$ & $4(28.6)$ & \\
Lack of arterial blood gas & $14(30.4)$ & $4(28.6)$ & \\
improvement & & & \\
Copious secretion & 0 & $3(21.4)$ & \\
Agitation & $1(2.2)$ & $1(7.1)$ & \\
Large leaks & $2(4.4)$ & 0 & \\
Patients' discomfort or refuse & $6(13.3)$ & $2(14.3)$ & \\
Length of NIV (day) & $4.78 \pm 0.39$ & $2.27 \pm 0.38$ & 0.001 \\
Length of ICU stay (day) & $16.1 \pm 1.50$ & $17.8 \pm 2.80$ & 0.210 \\
ICU mortality & $19(15.0)$ & $3(11.5)$ & 0.769 \\
Hospital mortality & $28(22.0)$ & $7(26.9)$ & 0.590 \\
\hline
\end{tabular}

Values are presented as number (\%) or mean \pm standard deviation. NIV: noninvasive ventilation; MV: mechanical ventilation; HFNC: highflow nasal cannula; ICU: intensive care unit.
$\mathrm{P}=0.009)$. In the control group, the pressure support ventilation (PSV) mode was used in 56 patients (84.8\%). In the sedation group, the pressure control ventilation mode was used in 13 patients (50\%) and the PSV mode was used in 10 patients (38.5\%) $(\mathrm{P}=0.016)$.

The mean IPAP was $14.5 \pm 0.36 \mathrm{~cm} \mathrm{H}_{2} \mathrm{O}$ in the control group and $14.1 \pm 0.49 \mathrm{~cm} \mathrm{H}_{2} \mathrm{O}$ in the sedation group $(\mathrm{P}=0.386)$, and the mean EPAP was $5.05 \pm 0.12 \mathrm{~cm} \mathrm{H}_{2} \mathrm{O}$ and $4.92 \pm 0.37 \mathrm{~cm}$ $\mathrm{H}_{2} \mathrm{O}(\mathrm{P}=0.229)$, respectively. The tidal volume was $432 \pm 16.1$ $\mathrm{ml}$ in the control group and $529 \pm 51.0 \mathrm{ml}$ in the sedation group $(\mathrm{P}=0.05)$.

\section{Clinical Outcomes and Complications}

Forty-six patients (35.7\%) in the control group and 14 patients $(53.8 \%)$ in the sedation group had failed NIV treatment $(\mathrm{P}=0.086)$. In the control group, 22 patients $(17.1 \%)$ underwent tracheal intubation and maintained MV. In the sedation group, tracheal intubation was performed in eight patients (30.8\%). The most common cause of NIV failure in both groups was inadequate efficacy (i.e., no clinical improvement or no improvement in ABGA). In the sedation group, three cases $(21.4 \%)$ had failed NIV due to copious secretions. The length of ICU stay was $16.1 \pm 1.5$ days in the control group and $17.8 \pm 2.80$ days in the sedation group $(P=0.210)$. The length of the NIV period was $4.78 \pm 0.39$ days in the control group and $2.28 \pm 0.38$ days in the sedation group $(\mathrm{P}=0.001)$. In the sedation group, the length of the NIV period was significantly shorter than that of the control group. However, this was due to the NIV weaning failure being more frequent in the sedation group (Table 4).

Table 5. Safety outcomes during NIV between the two groups

\begin{tabular}{|c|c|c|c|}
\hline Outcome & $\begin{array}{c}\text { Control } \\
(n=129)\end{array}$ & $\begin{array}{c}\text { Sedation } \\
(n=26)\end{array}$ & P-value \\
\hline No. of complications & $45(34.9)$ & $9(34.6)$ & 0.979 \\
\hline \multicolumn{4}{|l|}{ Complication during NIV } \\
\hline Skin erythema & $20(15.5)$ & $6(23.1)$ & 0.389 \\
\hline Abdominal distension & $6(4.7)$ & $1(3.8)$ & 1.000 \\
\hline Dry mouth & $5(3.9)$ & $1(3.8)$ & 1.000 \\
\hline Aspiration & $5(3.9)$ & 0 & 0.590 \\
\hline Large leak & $16(12.4)$ & $1(3.8)$ & 0.309 \\
\hline Claustrophobia & $4(3.1)$ & 0 & 1.000 \\
\hline Nasal congestion or sinus pain & 0 & $1(3.8)$ & 0.168 \\
\hline Mucosal plugging & $1(0.8)$ & 0 & 1.000 \\
\hline
\end{tabular}

Values are presented as number (\%).

NIV: noninvasive ventilation.

aFisher exact test. 
Table 6. Medication use during NIV in the intervention group

\begin{tabular}{lc}
\hline Medication & Sedation group $(n=26)$ \\
\hline Remifentanil & $15(57.7)$ \\
Dexmedetomidine & $8(30.8)$ \\
Fentanyl & $1(3.8)$ \\
Midazolam & $1(3.8)$ \\
Morphine & $1(3.8)$ \\
\hline
\end{tabular}

Values are presented as number (\%).

NIV: noninvasive ventilation.

Complications of NIV were reported in 45 patients (34.9\%) in the control group and nine patients (34.6\%) in the sedation group. The most commonly reported complication during the NIV period was skin erythema, with 20 cases (15.5\%) occurring in the control group and six (23.1\%) in the sedation group (Table 5).

\section{Pharmacologic Use and Type}

Of all the patients, 26 patients (16.7\%) received a sedative (or analgesic) during NIV treatment with remifentanil $(\mathrm{n}=15)$ and dexmedetomidine $(n=8)$ being the most commonly used (Table 6).

\section{DISCUSSION}

Our study contains several important findings. First, we found that $16.8 \%$ of patients with NIV treatment received pain or sedation therapy in Korean ICUs. In the sedation group, the most common cause for the implementation of NIV was postextubation respiratory failure $(57.7 \%)$. In the same group, the most common cause of ICU admission was pneumonia treatment $(53.8 \%)$. Second, while the rate of NIV failure was $35.7 \%$ in the control group and $53.8 \%$ in the sedation group, the difference was not statistically significant. Furthermore, the rate of tracheal intubation was $\mathbf{1 7 . 1 \%}$ in the control group and $30.8 \%$ in the sedation group. NIV was primarily applied to the sedation group post-extubation, which may be the result of extubation failure. This hypothesis is supported by the observation that a portion of the NIV failures in the sedation group were due to copious secretions (21.4\%). Third, the length of NIV use was 2.5 days shorter in the sedation group when compared to the control group. The NIV failure rate in the sedation group was high, which may explain this shorter NIV duration. However, there were no differences in the length of ICU stay, ICU mortality, or hospital mortality between the two groups. Finally, the incidence of NIV complications was $34.9 \%$ in the control group and $34.6 \%$ in the sedation group, which is not a significant difference. Skin erythema was the most common complication of NIV in both groups.

There are several limitations in this study. First, the number of patients who underwent sedation in our total patient population was insufficient. Devlin et al. [18] conducted a survey of 2,985 physicians in North America and Europe and found that $41 \%$ used sedative drugs in NIV in North America and $24 \%$ in Europe. However, only $17 \%$ of patients in Korean ICUs who underwent NIV used sedative drugs. The authors [18] reported that the regional differences in the use of sedative drugs in NIV treated patients was due to differences in physician experience in applying NIV, experience in sedation monitoring, presence of a sedation protocol, and the nurse-to-patient ratio. In a survey by Devlin et al. [18], the most widely used classes of sedation drugs were benzodiazepines (33\%) and opioids (29\%), and the most influential factors determining the choice of sedative were clinical experience with the agent (35\%) and a lack of an effect on respiratory drive (22\%). In our study, the most commonly used sedative drugs during NIV were remifentanil $(57.7 \%$ [15/26]) and dexmedetomidine (30.8\% [8/26]). However, the reasons for choosing these specific pharmacologics and the most efficacious sedative drug dose were not investigated. Therefore, further investigation and analysis of the most efficacious sedative drug doses and the specific reasons for the selection of the drugs is needed in future studies. Third, the reasons for choosing NIV treatment between the control and the sedation groups were different in our study. It is well-known that the most common indications for NIV are the acute exacerbation of COPD and cardiogenic pulmonary edema. In our study, the primary reason for NIV was hypercapnic respiratory failure $(63.6 \%)$ in the control group and post-extubation for weaning (57.7\%) in the sedation group. This difference may be due to the required maintenance of sedation during NIV after extubation in patients who used sedative drugs during MV treatment. In addition, NIV after extubation is clinically more likely to result in lower voluntary respiration weaning rates and higher rates of re-intubation. This could then explain the higher NIV failure rate in the sedation group. It also suggests that clinicians should be intensive in their observations of patients during the use of sedation. Despite these limitations, the present study provides the first extensive survey of current sedation practices in patients treated with NIV in Korea ICUs.

In conclusion, for patients who were admitted to Korean ICUs and treated with NIV, the use of sedatives did not present any obvious harmful effects in regard to ICU hospital stay, ICU mortality or hospital mortality, or NIV complications. 
Therefore, we suggest the application of analgosedation may not be harmful for patients who are undergoing NIV.

\section{CONFLICT OF INTEREST}

Jae Hwa Cho has been the editor-in-chief of Acute and Critical Care since 2016 and an editorial board member since 2008.

\section{ACKNOWLEDGMENTS}

This work was supported by a 2017 clinical research grant from the Korea Academy of Tuberculosis and Respiratory Disease. The funders had no role in the study design, data collection and analysis, or manuscript preparation.

We thank the following investigators for their participation in this study: Jin Woo Kim (Uijeongbu St. Mary's Hospital, College of Medicine, The Catholic University of Korea), Jong Hoo Lee (Jeju National University Hospital), Tae Oak Kim (Chonnam National University Hospital), Yun Mi Sin (Chungbuk National University), and Jik Hwan Ha (Incheon St. Mary's Hospital, College of Medicine, The Catholic University of Korea).

\section{ORCID}

$\begin{array}{ll}\text { Taehee Kim } & \text { https://orcid.org/0000-0002-3673-7595 } \\ \text { Jung Soo Kim } & \text { https://orcid.org/0000-0001-6603-6768 } \\ \text { Eun Young Choi } & \text { https://orcid.org/0000-0003-2974-5447 } \\ \text { Youjin Chang } & \text { https://orcid.org/0000-0002-4838-466X } \\ \text { Won-Il Choi } & \text { https://orcid.org/0000-0001-7705-0098 } \\ \text { Jae-Joon Hwang } & \text { https://orcid.org/0000-0003-1832-1024 } \\ \text { Jae Young Moon } & \text { https://orcid.org/0000-0001-8724-6289 } \\ \text { Kwangha Lee } & \text { https://orcid.org/0000-0001-9878-201X } \\ \text { Sei Won Kim } & \text { https://orcid.org/0000-0002-2798-421X } \\ \text { Hyung Koo Kang } & \text { https://orcid.org/0000-0001-9671-0944 } \\ \text { Yun Su Sim } & \text { https://orcid.org/0000-0002-3746-4947 } \\ \text { Tai Sun Park } & \text { https://orcid.org/0000-0001-7383-7934 } \\ \text { Seung Yong Park } & \text { https://orcid.org/0000-0002-3774-4375 } \\ \text { Sunghoon Park } & \text { https://orcid.org/0000-0001-7004-6985 } \\ \text { Jae Hwa Cho } & \text { https://orcid.org/0000-0002-3432-3997 }\end{array}$

\section{AUTHOR CONTRIBUTIONS}

Conceptualization: TK, JSK, EYC, YC, SP, JHC. Data curation: all authors. Formal analysis \& Methodology: TK, JSK, SP, JHC. Visualization: TK, JHC. Writing-original draft: TK, SP, JHC. Writing-reviewing \& editing: all authors.

\section{REFERENCES}

1. Walkey AJ, Wiener RS. Use of noninvasive ventilation in patients with acute respiratory failure, 2000-2009: a populationbased study. Ann Am Thorac Soc 2013;10:10-7.

2. Girou E, Brun-Buisson C, Taillé S, Lemaire F, Brochard L. Secular trends in nosocomial infections and mortality associated with noninvasive ventilation in patients with exacerbation of COPD and pulmonary edema. JAMA 2003;290:2985-91.

3. Hilbert G, Navalesi P, Girault C. Is sedation safe and beneficial in patients receiving NIV? Yes. Intensive Care Med 2015;41: 1688-91.

4. Carron M, Freo U, BaHammam AS, Dellweg D, Guarracino F, Cosentini R, et al. Complications of non-invasive ventilation techniques: a comprehensive qualitative review of randomized trials. Br J Anaesth 2013;110:896-914.

5. Conti G, Arcangeli A, Antonelli M, Cavaliere F, Costa R, Simeoni F, et al. Sedation with sufentanil in patients receiving pressure support ventilation has no effects on respiration: a pilot study. Can J Anaesth 2004;51:494-9.

6. Ethuin F, Boudaoud S, Leblanc I, Troje C, Marie O, Levron JC, et al. Pharmacokinetics of long-term sufentanil infusion for sedation in ICU patients. Intensive Care Med 2003;29:191620

7. Constantin JM, Schneider E, Cayot-Constantin S, Guerin R, Bannier F, Futier E, et al. Remifentanil-based sedation to treat noninvasive ventilation failure: a preliminary study. Intensive Care Med 2007;33:82-7.

8. Akada S, Takeda S, Yoshida Y, Nakazato K, Mori M, Hongo T, et al. The efficacy of dexmedetomidine in patients with noninvasive ventilation: a preliminary study. Anesth Analg 2008; 107:167-70.

9. Clouzeau B, Bui HN, Vargas F, Grenouillet-Delacre M, Guilhon E, Gruson D, et al. Target-controlled infusion of propofol for sedation in patients with non-invasive ventilation failure due to low tolerance: a preliminary study. Intensive Care Med 2010;36:1675-80

10. Rocco M, Conti G, Alessandri E, Morelli A, Spadetta G, Laderchi A, et al. Rescue treatment for noninvasive ventilation failure due to interface intolerance with remifentanil analgosedation: a pilot study. Intensive Care Med 2010;36:2060-5.

11. Huang Z, Chen YS, Yang ZL, Liu JY. Dexmedetomidine versus midazolam for the sedation of patients with non-invasive ventilation failure. Intern Med 2012;51:2299-305.

12. Nam H, Cho JH, Choi EY, Chang Y, Choi WI, Hwang JJ, et al. Current status of noninvasive ventilation use in Korean intensive care units: a prospective multicenter observational study. 
Tuberc Respir Dis (Seoul) 2019;82:242-50.

13. Demoule A, Chevret S, Carlucci A, Kouatchet A, Jaber S, Meziani $\mathrm{F}$, et al. Changing use of noninvasive ventilation in critically ill patients: trends over 15 years in francophone countries. Intensive Care Med 2016;42:82-92.

14. Demoule A, Girou E, Richard JC, Taillé S, Brochard L. Increased use of noninvasive ventilation in French intensive care units. Intensive Care Med 2006;32:1747-55.

15. Shaheen M, Daabis RG, Elsoucy H. Outcomes and predictors of success of noninvasive ventilation in acute exacerbation of chronic obstructive pulmonary disease. Egypt Bronchology 2018;12:329-39.
16. Moretti M, Cilione C, Tampieri A, Fracchia C, Marchioni A, Nava S. Incidence and causes of non-invasive mechanical ventilation failure after initial success. Thorax 2000;55:819-25.

17. Soo Hoo GW, Santiago S, Williams AJ. Nasal mechanical ventilation for hypercapnic respiratory failure in chronic obstructive pulmonary disease: determinants of success and failure. Crit Care Med 1994;22:1253-61.

18. Devlin JW, Nava S, Fong JJ, Bahhady I, Hill NS. Survey of sedation practices during noninvasive positive-pressure ventilation to treat acute respiratory failure. Crit Care Med 2007;35: 2298-302. 